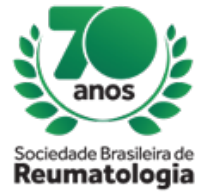

\title{
LOW BONE MASS IN A YOUNG PATIENT CAUSED BY IDIOPATHIC HYPERCALCIURIA: A CASE REPORT
}

Guilherme Bezerra Ferreira (Universidade Federal de Mato Grosso, Rondonópolis, MT, Brasil), Gustavo Martins Simião (Universidade Federal de Mato Grosso, Rondonópolis, MT, Brasil), Josiane Neves Coelho Marques (Universidade Federal de Mato Grosso, Rondonópolis, MT, Brasil)

\section{BACKGROUND}

Idiopathic hypercalciuria is one of the most complex physiopathological and factorial therapies for the formation of renal calculi and bone demineralization, among others.

Its pathophysiology consists of four mechanisms that can act simultaneously in the same individual: intestinal hyperabsorption of calcium, primary renal calcium loss, tubular phosphate loss and increased bone resorption. It is believed that the mechanisms involved in the condition may result in increased osteoclast activity, potentiating bone remodeling and consequent reduction of bone mass, resulting in low bone mass and osteoporosis in young people and formation of renal lithiasis.

\section{CASE REPORT}

F.R.F.B, female, 33 years old, reports that during a research project, she performed bone densitometry analysis by means of dual-energy x-ray absorptiometry (DXA) with osteoporosis findings. She subsequently repeated DXA with similar diagnosis (sic). Patient seeks endocrinologist claiming not to have continued with the propaedeutic and without initiation of therapy. Extensive propaedeutic was initiated for secondary causes of low bone mass in a previously healthy young patient. DXA of $(2 / 6 / 2016)$ with Z score -2.4, total femur -2.2. DXA (4/8/2016): Z score -2.8, femoral neck -1.9 and total -2.0, BMD $0.741 \mathrm{~g} / \mathrm{cm} 2$. Laboratory exams without changes except for 24-hour high calciuria: volume $1200 \mathrm{ml}$, creatinine $1.428 \mathrm{mg}$ VR $600-1800 \mathrm{mg}$ calciuria: $403 \mathrm{mg} / 24 \mathrm{~h}$ VR up to $250 \mathrm{mg}$.

In view of the diagnosis of low bone mass due to idiopathic hypercalciuria, calcium supplementation $500 \mathrm{mg} /$ day, vitamin D 7,000 $\mathrm{lU} /$ week and hydrochlorothiazide $12.5 \mathrm{mg} /$ day were initiated in addition to the orientation of bodybuilding and physical activities of impact for muscle strengthening.

In subsequent consultation, the patient returns with new densitometry and reports abandonment of physical activity and the use of hydrochlorothiazide, maintaining only the use of the indicated supplementation. DXA (10/11/2017): Z score column -2.6, femoral neck -2.5 and total femur -2.2, BMD $0.718 \mathrm{~g} / \mathrm{cm} 2$. There was a loss of bone mass of $3.2 \%$ in relation to the $4 / 8 / 16$ examination. Calciuria $24-$ hour (11/27/2017): $153 \mathrm{mg} / 24 \mathrm{hr}$ VR: up to $250 \mathrm{mg}$, vol $1530 \mathrm{ml}$.

\section{CONCLUSION}

The described scenario corroborates the hypothesis of idiopathic hypercalciuria as a cause of low bone mass in a young patient with no other risk factor or clinical condition that explains this diagnosis. It exposes the need for extensive propaedeutics to exclude other causes and reinforces the need for therapy goes beyond the correction of hypercalciuria, aiming at interrupting the loss and favoring improvement of bone mass in order to prevent osteoporosis. 